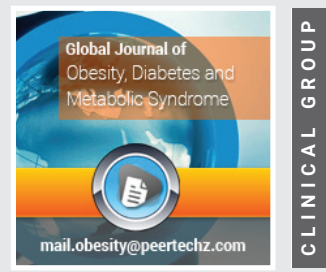

\title{
Physical Literacy for life: the facts, the trends, and the effects
}

Received: 17 March, 2020

Accepted: 11 April, 2020

Published: 13 April, 2020

*Corresponding author: Fabiano Henrique Rodrigues Soares, PhD, Health Science Center, Federal University of Rio Grande do Norte, Natal, Rio Grande do Norte, Brazil, E-mail: fabianohrsoares@outlook.com

https://www.peertechz.com

\section{Check for updates}

\section{Fabiano Henrique Rodrigues Soares* \\ Health Science Center, Federal University of Rio Grande do Norte, Natal, Rio Grande do Norte, Brazil}

\section{Summary}

As sedentary related cardiometabolic outcomes have increased worldwide for the past decades, stimulating a physically active lifestyle among younger populations is imperative. Physical education, as a key tool to develop physical literacy (PL), can reverse this global trend using different approaches. Observational and experimental research must be conducted to address the multidimensional aspects of PL. This proposal aims to prepare, conduct research and present results about affective, physical, cognitive and behavioral aspects PL. There should be a commitment to attracting, developing, and supporting outstanding undergraduate and graduate students and postdoctoral fellows through interdisciplinary research and interaction with the private and public sectors. The aim is to promote knowledge for diverse communities so they can understand the importance of $\mathrm{PL}$ and can make better decisions regarding physical activity throughout life.

\section{Context}

Overweight and obesity pandemic represents a major public health concern with global scope, heterogeneous patterns, wide-ranging impacts, lack of a single cause, and failure of single solutions [1]. The prevalence of obesity has increased for the past three decades; doubling in more than 70 countries with an estimated 600 million obese adults worldwide [2]. The obese phenotype remains a well-established risk factor for numerous chronic diseases and disability [3] and contributed to over 4 million deaths in 2015, 2.7 million of them related to cardiovascular disease [2]. Such burden of obesity-related diseases is heavier among women as female obesity and severe obesity prevalence are higher than in men of all age ranges surpassing $21 \%$ and $9 \%$, respectively [2,4]. Even though overweight and obesity are adaptations to an obesogenic environment, susceptible only to policy interventions, health promotion programs characterized by increased physical activity and a balanced diet can influence behavior patterns toward a healthier lifestyle [5].

During human development, children and adolescents go through various biological (age and maturation), sociocultural (distinct social roles, incentives from friends, family, and teachers) and psychological (self-image, motivation and lack of knowledge and interest) processes that positively or negatively influence physical activity habits in adulthood. Recent findings indicate a prevalence of sedentary behavior among children and adolescents of 57\% [6] and this behavior is positively associated with increased cardiometabolic risk [7]. Loss of motivation may be associated with the discovery of other interests, behaviors and personality traits that arise with maturation. In epidemiological terms, as the first level of prevention is health promotion, encouraging physical activity in the juvenile population can mitigate cardiometabolic risk during adulthood.

Physical activity should be promoted inside and outside school settings through games, gymnastics, dances, sports, and fighting games that could embrace the cultural aspects of the student's environment to reverse the above-cited scenario. Physical Education is the mean by which Physical Literacy (PL) can be properly disseminated among children and adolescents aiming at promoting healthier outcomes throughout the life span. The most accepted definition of PL was defined by the International Physical Literacy Association (IPLA) and was adopted by a consortium of Canadian institutions. It states that PL is "the motivation, confidence, physical competence, knowledge and understanding to value and take responsibility for engagement in physical activities for life" [8]. This construct is directly associated with aspects of physical education such as motor and cognitive skill, health and skill-related fitness, 
intrinsic motivation, self-confidence and self-efficacy, and application of literacy skills throughout life [9].

We propose a plan aimed at creating and establishing a network of research and implementation of research findings in academic and community-based settings to promote PL through a variety of physical and leisure activities. The plan embraces a diversity of subjects related to PL and includes the physiological and functional capacity approach, the motor skills development approach, and the psychological and behavioral change approach, especially the affective and cognitive aspects of PL.

Several lines of research can be derived from this plan and would include the description (sectional studies) of the PL characteristics in diverse populations, the identification (observational longitudinal studies) of external factors - social, emotional, political, biological, and educational - that could be determinants and/or be influenced by the proper development of PL. Finally, interventions (individual and communitybased experimental studies) that could examine if PL-focused programs are effective and could result in lifelong application and if it properly enables people to understand its importance of PL so that they can make better decisions throughout life.

Those lines of research would accommodate personnel of different levels. Undergraduate students would focus mainly on the descriptive projects, the graduate students would be mainly enrolled in risk factor assessment through observational projects, and the postdoctoral fellows would be enrolled mainly in the experimental projects. All addressing research questions that have a clear connection with PL. Whenever suitable, systematic reviews of literature would be conducted to create a robust body of evidence regarding most of the aspects of PL.

\section{Engagement with research users and communication of results}

Research training would encourage Highly Qualified Personnel (HQP) to participate in science outreach activities, interdisciplinary research, and regular participation in research seminar series, presentations to peers for feedback and to engage in fruitful discussions. The University should contribute to create opportunities for informal discussions with the community and encourage professional development. This way, Universities would be able to establish extension programs to reach a broader community as a means of translating the research findings to diverse settings and strengthen connections with the private and public sectors. Regular meetings would be held with other groups within the universities and broader communities to encourage knowledge exchange, research findings sharing and problem-solving approaches. It will allow HQP to gain experience in presenting for and discussing with a varied audience outside the core research area and develop co-authorship, publications, patents, and key presentations on local, provincial, national and international events.

\section{HQP training plan}

A training philosophy needs to be committed to attracting, developing and supporting outstanding HQP (undergraduate, graduate, and postdoctoral fellows). The research plan should be designed such that HQP learn tools and methods of high relevance to the Universities and help them develop skills that can be transferred to non-academic contexts. Trainees would be encouraged to communicate, be creative, and innovate. It will prepare them for impactful careers inside and outside academia.

HQP would participate in different aspects of this program to develop an understanding of how different projects contribute to the short-term/long-term goals of the main research plan. This would help them appreciate the implications of their research at different levels: academic, practical, community and societal.

The approach to mentorship deeds to be very structured (Table 1). Including regular meetings with HQP individually (at least once a week) and in groups (at least twice a month) to discuss their progress, guide them in professional development (e.g. internship and elective course selections, selection of conferences, and thesis support and revisions). All HQP positions in these research groups should adhere to University's inclusion and diversity policies and expectations for a comprehensive work environment.

This approach would also enhance training by ensuring a collaborative and interdisciplinary atmosphere. If a project goes beyond one's area of expertise, there would be an encouragement for co-supervision to support, maximize, and complement methodology training and knowledge gain.

Table 1: HQP training structure.

\begin{tabular}{|c|c|c|c|c|c|}
\hline $\begin{array}{l}\text { HQP Selection and } \\
\text { Assessment }\end{array}$ & Project Selection & Research Specific Training & Career Specific Training & Research Development & Research Communication \\
\hline $\begin{array}{l}\text { Jndergraduate } \\
\text { Idents. } \\
\text { Graduate Students - } \\
\text { c/Ph.D. } \\
\text { ostdoctoral fellows. } \\
\text { Technicians and other } \\
\text { earch personnel } \\
\text { tside academia. }\end{array}$ & $\begin{array}{l}\text { 1. Preparation and } \\
\text { dissemination of } \\
\text { research project } \\
\text { selection notices. } \\
\text { 2. Adjustments to } \\
\text { selected projects to suit } \\
\text { the research program } \\
\text { needs. }\end{array}$ & $\begin{array}{l}\text { 1. Preparing drafts of grant } \\
\text { applications and ethics } \\
\text { approval. } \\
\text { 2. Brainstorming activities, } \\
\text { discussions, and project } \\
\text { design knowledge. } \\
\text { 3. Prioritizing and working } \\
\text { on strict deadlines. } \\
\text { 4. Interdisciplinary research } \\
\text { and interaction with the }\end{array}$ & $\begin{array}{l}\text { 1. International and } \\
\text { intersectoral experience. } \\
\text { 2. Interaction with the private } \\
\text { and public sectors. } \\
\text { 3. Training in inclusive } \\
\text { strategies and outreach } \\
\text { activities to under- } \\
\text { represented or disadvantaged } \\
\text { groups. }\end{array}$ & $\begin{array}{l}\text { 1. Collecting data and } \\
\text { analyzing results, assessing } \\
\text { the quality, validity, and } \\
\text { reliability of the database. } \\
2 . \text { Achieving long and short- } \\
\text { term } \\
\text { goals and regularly } \\
\text { evaluating progress. }\end{array}$ & $\begin{array}{l}\text { 1. Science outreach activities. } \\
\text { 2. Production of research } \\
\text { papers. } \\
\text { 3. Delivering of research } \\
\text { seminars and conferences. } \\
\text { 4. Community-based informal } \\
\text { discussions for research } \\
\text { dissemination outside } \\
\text { academia. }\end{array}$ \\
\hline
\end{tabular}

Citation: Rodrigues Soares FH (2020) Physical Literacy for life: the facts, the trends, and the effects . Glob J Obes Diabetes Metab Syndr 7(1): 009-011. 
The plan should enable students and postdoctoral fellows to acquire valuable skills, such as leadership and teamwork, communication and dissemination of research findings; critical thinking, time management and prioritizing, and analytical skills.

\section{Conclusion}

Universities around the world should stimulate a research agenda that embraces every aspect of PL during the entire lifespan. The development and dissemination of a strong knowledge base of the benefits of a more active lifestyle are paramount to create healthier communities. By crafting a network of research, Universities would help their communities by developing and disseminating culturally focused knowledge.

\section{References}

1. Lee BY, Bartsch SM, Mui Y, Haidari LA, Spiker ML, et al. (2017) A systems approach to obesity. Nutr Rev 75: 94-106. Link: https://bit.ly/34wWqnS

2. Afshin A, Forouzanfar MH, Reitsma MB, Sur P, Estep K, et al. (2017) Health Effects of Overweight and Obesity in 195 Countries over 25 Years. N Engl $J$ Med 377: 13-27. Link: https://bit.ly/2Rsnboj

3. Chang VW, Alley DE, Dowd JB (2017) Trends in the Relationship Between
Obesity and Disability, 1988-2012. Am J Epidemiol 186: 688-695. Link: https://bit.ly/2K1UQkE

4. (NCD-RisC) NRFC (2016) Trends in adult body-mass index in 200 countries from 1975 to 2014: a pooled analysis of 1698 population-based measurement studies with $19 \cdot 2$ million participants. Lancet 387: 1377-1396. Link: https://bit.ly/3efMpjx

5. Swinburn BA, Sacks G, Hall KD, McPherson K, Finegood DT, et al. (2011) The global obesity pandemic: shaped by global drivers and local environments. Lancet 378: 804-814. Link: https://bit.ly/2XvtkDP

6. Harvey JA, Chastin SF, Skelton DA (2013) Prevalence of sedentary behavior in older adults: a systematic review. Int J Environ Res Public Health 10: 66456661. Link: https://bit.ly/2ybHvTU

7. Carson V, Tremblay MS, Chaput JP, McGregor D, Chastin S (2019) Compositional analyses of the associations between sedentary time, different intensities of physical activity, and cardiometabolic biomarkers among children and youth from the United States. PLoS One 14: e0220009. Link: https://bit.ly/2VsUhw6

8. Tremblay MS, Costas-Bradstreet C, Barnes JD, Bartlett B, Dampier D, et al. (2018) Canada's Physical Literacy Consensus Statement: process and outcome. BMC Public Health 18: 1034. Link: https://bit.ly/2xsey6a

9. Corbin CB (2016) Implications of physical literacy for research and practice: A commentary. Res Q Exerc Sport 87: 14-27. Link: https://bit.ly/34wWS5y

\footnotetext{
Discover a bigger Impact and Visibility of your article publication with Peertechz Publications

\section{Highlights}

* Signatory publisher of ORCID

* Signatory Publisher of DORA (San Francisco Declaration on Research Assessment)

* Articles archived in worlds' renowned service providers such as Portico, CNKI, AGRIS, TDNet, Base (Bielefeld University Library), CrossRef, Scilit, J-Gate etc.

* Journals indexed in ICMJE, SHERPA/ROMEO, Google Scholar etc.

* OAI-PMH (Open Archives Initiative Protocol for Metadata Harvesting)

* Dedicated Editorial Board for every journa

* Accurate and rapid peer-review process

* Increased citations of published articles through promotions

* Reduced timeline for article publication

Submit your articles and experience a new surge in publication services (https://www.peertechz.com/submission).

Peertechz journals wishes everlasting success in your every endeavours.
}

Copyright: @ 2020 Rodrigues Soares FH. This is an open-access article distributed under the terms of the Creative Commons Attribution License, which permits unrestricted use, distribution, and reproduction in any medium, provided the original author and source are credited.

Citation: Rodrigues Soares FH (2020) Physical Literacy for life: the facts, the trends, and the effects . Glob J Obes Diabetes Metab Syndr 7(1): 009-011. 